\title{
The acute lethality and endocrine effect of 1,2,3,7,8-PeCDD in juvenile goldfish (Carassius auratus) in vivo
}

\author{
YANG Yongbin $^{1,3}$, LIU Zhengtao ${ }^{2}$, ZHENG Minghui $^{1, *}$, ZHAO Yanyan ${ }^{3}$, \\ WANG Liang ${ }^{3}$, SUN Wei ${ }^{3}$, XIAO Feng ${ }^{3}$ \\ 1. State Key Laboratory of Environmental Chemistry and Ecotoxicology, Research Center for Eco-Environmental Sciences, \\ Chinese Academy of Sciences, Beijing 100085, China. E-mail: yang28yongbin@163.com \\ 2. China Research Academy of Environmental Sciences, Beijing 100012, China \\ 3. Health Science Center, Hebei University, Baoding 071000, China
}

Received 3 April 2007; revised 27 April 2007; accepted 9 May 2007

\begin{abstract}
1,2,3,7,8-PeCDD was administrated to juvenile goldfish (Carassius auratus) by peritoneal injections to explore the acute lethality and endocrine effects of 1,2,3,7,8-PeCDD in vivo. The value of acute median lethal dosage $\left(\mathrm{LD}_{50}\right)$ of 1,2,3,7,8-PeCDD was determined in acute lethality tests. The endocrine effect of $1,2,3,7,8-\mathrm{PeCDD}$, whose exposed concentrations were determined based on the $\mathrm{LD}_{50}(1.84$ $\mathrm{mg} / \mathrm{kg}$ ), was studied by measuring the plasma vitellogenin (Vtg) content in juvenile male goldfish with enzyme-linked immunosorbent assays (ELISA). Due to its significant induction of the plasma Vtg after one week's exposure in vivo in the $1 / 2 \mathrm{LD}_{50}$ and $\mathrm{LD}_{30}$ groups, $1,2,3,7,8$-PeCDD might be one of the important contributors to the estrogenic effect of PCDDs in the environment. The values of $1 / 2$ $\mathrm{LD}_{50}$ and $\mathrm{LD}_{30}$ were within the range of the effective dosages of $1,2,3,7,8-\mathrm{PeCDD}$, indicating that there was a certain relationship between the estrogenic effective dosages and the $\mathrm{LD}_{50}$.
\end{abstract}

Key words: 1,2,3,7,8-PeCDD; goldfish; endocrine effect; vitellogenin (Vtg); acute lethality; ELISA

\section{Introduction}

Polychlorinated dibenzo- $p$-dioxins (PCDDs) including a group of 75 essentially planar, aromatic chemicals characterized by high octanol/water partition coefficients $\left(K_{\text {ow }}\right)$, extremely low water solubility and low vapor pressures (Fletcher and Mc, 1993; Geyer et al., 2000), are members of the halogenated aryl hydrocarbon family. PCDDs that exist normally as complex mixtures in the environment worldwide are by-products from the incineration of industrial and municipal wastes, the production of the chlorinated phenols and chlorine bleaching in paper mills. The PCDDs with four and more chlorine atoms in the lateral (2, 3, 7 and 8) positions are generally very resistant to chemical and biological degradation (Fiedler et al., 1990). The toxicity of complex mixtures containing PCDDs is often assessed by toxic equivalency factors (TEFs), which are based on the induction of the aryl hydrocarbon receptor (AHR) and suggested by the World Health Organization (WHO) (Van den Berg et al., 2006). WHO-TEFs are used to compare the potency of each congener related to that of 2,3,7,8-tetrachloro-dibenzo- $p$-dioxin (TCDD) that is the most potent isomer and thus is designated as the factor of 1 . The value of the PCDDs can be expressed as follows:

\footnotetext{
* Corresponding author. E-mail: zhengmh@rcees.ac.cn.
}

$\mathrm{TEQ}=\sum\left(\mathrm{TEF}_{i} \times \mathrm{Ex}_{i}\right)$

where, TEQ is the total toxic equivalent quantity, $\mathrm{TEF}_{i}$ is the TEF of the congener $i$, and $\mathrm{Ex}_{i}$ is the amount exposed of $i$.

Due to the high persistence and high lipophilicity $\left(K_{\text {ow }}\right)$, these toxic 2,3,7,8-substituted PCDDs may be concentrated through the food chain. Based on the toxicityequivalence analysis, 1,2,3,7,8-PeCDD was one of the most important contributors of TEQs of the PCDDs. And chlorine fingerprinting analysis showed that 1,2,3,7,8PeCDD was one of the dominant compounds that existed in the breast milk samples from Japan and European countries due to many years of industrialization and the consumption of freshwater fish (Furst et al., 1994; Noren and Meironyte, 2000; Sun et al., 2006; Vartiainen et al., 1997; Wittsiepe et al., 2007). It was also reported that the increasing blood levels of 1,2,3,7,8-PeCDD in old people eating more fish in their diet and the long half-life of 1,2,3,7,8-PeCDD (12.6 years) in the human body (Geyer $e t$ al., 2001, 2002; Gonzalez et al., 1998; Schuhmacher et al., 1998; Van den Berg et al., 1998; Wittsiepe et al., 2000). Therefore, the potential high bioaccumulation of PCDDs in the human body as a result of concentration in the food chain has aroused more and more attention recently, and 
it is thus necessary to study the multiple toxic endpoints of PCDDs in both humans and wildlife. It is concluded that the noncarcenogenic hazards of dioxins, which include the suppression of the immune system and thyroid, causing birth defects and the effects on the endocrine system such as the alteration of sexual development, is more important than their cancer hazard at current background doses to the general public. This has been suggested by many authoritative organizations, such as the US Environmental Protection Agency (USEPA), the WHO, the UK Food Standards Agency, and the Joint FAO/WHO Expert Committee on Food Additives (JECFA) (Greene et al., 2003; Keenan et al., 1991). Because 1,2,3,7,8-PeCDD might also cause a significant increase in estrogen secretion in the placental tissue, attention should be paid to its possible endocrine effects in aquatic organisms (Augustowska et al., 2003). Few data on the $\mathrm{LD}_{50}$ and estrogenic effects of $1,2,3,7,8-\mathrm{PeCDD}$ in aquatic organisms in vivo have been reported. In this study, goldfish that is one strain of the Carassius auratus, was chosen to be the testing organism. The main aims of this study were to explore the acute lethality and estrogenic effect in the juvenile goldfish exposed to 1,2,3,7,8-PeCDD in vivo. The content of plasma vitellogenin ( Vtg) was measured in juvenile male goldfish by enzyme-linked immunosorbent assays (ELISA). The reasons for choosing the Vtg as the test endpoint were based on the following three facts: Vtg is an egg yolk precursor protein synthesized in the liver of oviparous vertebrates before its transportation to the ovaries and incorporation into developing oocytes; Vtg is only produced by mature female fish as a yolk precursor under natural conditions; and Vtg can be induced to synthesize by male fish after being exposed to estrogen or xenoestrogenic compounds (Copeland et al., 1986; Denslow et al., 1999; Mommsen and Walsh, 1988; Sohoni et al., 2001; Specker and Sullivan, 1994; Wallace, 1978).

\section{Material and methods}

\subsection{Chemicals}

$17 \beta$-Estradiol $\left(\mathrm{E}_{2}\right)(98 \%$, Sigma, USA) and 1,2,3,7,8PeCDD (purity $>98 \%$ ), which was synthesized in the laboratory, were dissolved in peanut oil and stored at $4^{\circ} \mathrm{C}$. The rabbit anti-carp Vtg polyclonal antibody was kindly provided by Professor XU Ying from the Institute of Hydrobiology, Chinese Academy of Sciences.

\subsection{Fish}

Juvenile Carassius auratus (goldfish, Oranda), with mean body-length and weight $5.5 \pm 0.69 \mathrm{~cm}$ and $9.3 \pm$ $2.85 \mathrm{~g}$, respectively, were chosen as the test subject and purchased from a local fish farm. Prior to the experiments, the fish were acclimated for $10 \mathrm{~d}$ to dechlorinated water, whose $\mathrm{pH}$ was $7.0 \pm 0.1$, temperature $20 \pm 1^{\circ} \mathrm{C}$ under a $14 \mathrm{~h}$ light/10 h dark cycle, and whose hardness was about $100 \mathrm{mg} / \mathrm{L}$ as $\mathrm{CaCO}_{3}$. The fish were fed once daily in the morning with commercial dry pellets for goldfish. The mortality of the test fish was less than $5 \%$ of the population.

\subsection{Experimental design}

\subsubsection{Acute lethality tests}

After acclimatization, the fish were divided randomly into groups of ten fish $(n=10)$, weighed, and kept in a glass aquaria containing $60 \mathrm{~L}$ of water for the experiments in vivo in a semi-static system. After the range of toxicity was determined in the pretreatment experiments in fish conducted in this laboratory, the treatment groups received a single intraperitoneal injection of six different dosages of 1,2,3,7,8-PeCDD (1.0, 1.5, 1.7, 2.0, 2.3, and $2.5 \mathrm{mg} / \mathrm{kg})$ dissolved in peanut oil on the first day. Two groups of goldfish receiving injections of dechlorinated water (4 $\mathrm{ml} / \mathrm{kg})$ and peanut oil $(4 \mathrm{ml} / \mathrm{kg})$ were included as controls. Two replicates were used in each treatment group and contrast group. Tested organisms were fed once daily during the test periods. The number of fish that died in a 14-d period after a single dosage was tabulated. All tests were carried out repeatedly. The median lethal dosage $\left(\mathrm{LD}_{50}\right)$ of $1,2,3,7,8$-PeCDD was calculated by the method of graphical interpolation recommended by the Organization for Economic Co-operation and Development (OECD, 1996).

\subsubsection{Endocrine effect tests}

The exposure dosages testing the estrogenic effects of $1,2,3,7,8$-PeCDD were selected based on the value of its $\mathrm{LD}_{50}$ obtained from the acute lethal tests. The juvenile fish were separated randomly into groups of 10 fish and weighed. Two groups of goldfish receiving injections of dechlorinated water $(4 \mathrm{ml} / \mathrm{kg})$ and peanut oil $(4 \mathrm{ml} / \mathrm{kg})$ were included as controls. Seven and fourteen days following a single intraperitoneal injection of 1,2,3,7,8-PeCDD $\left(1 / 4 \mathrm{LD}_{50}, 1 / 2 \mathrm{LD}_{50}\right.$, and $\left.\mathrm{LD}_{30}\right)$ and $\mathrm{E}_{2}(1 \mathrm{mg} / \mathrm{kg}$, serving as a positive control), dissolved in peanut oil on the first day, the goldfish were euthanized via a blow to the head, and then separated by sex. The blood of the male goldfish was collected immediately after the blow in chilled heparinized syringes and immediately transferred to vials containing the protease inhibitor aprotinin (2 trypsin inhibitor units $/ \mathrm{ml}$ ). The serum was separated from the blood by $8000 \mathrm{r} / \mathrm{min}$ for $15 \mathrm{~min}\left(4^{\circ} \mathrm{C}\right)$ and stored at $-80^{\circ} \mathrm{C}$ for later studies. Six male samples were obtained for every group. For every treatment and control group, 10 fish were placed in a glass aquaria containing $60 \mathrm{~L}$ of water in three replicates, giving at least a total of 30 animals per treatment dosage or control. Four replicates were used in the group of $\mathrm{LD}_{30}$ compensating for the loss of organisms. Tested organisms were fed once daily during the test periods. All tests were carried out repeatedly.

\subsection{Vitellogenin determination by ELISA}

The method described below was based on the combination of the Vtg adsorbed on the microtiter plate in the plasma sample and the anti-Vtg antibodies, according to the principle of indirect ELISA. The concentrations of Vtg in the plasma were determined with the assay procedure described below. A 96-well microtiter plate (Canada JET Biochemical Int'1., Inc.) was coated with $100 \mu$ l of diluted 
plasma samples in $0.01 \mathrm{~mol} / \mathrm{L}$ carbonate buffer at $\mathrm{pH}$ 9.6. Appropriate wells were coated with standard purified Vtg diluted with $0.01 \mathrm{~mol} / \mathrm{L}$ carbonate buffer at $\mathrm{pH} 9.6$ in a series from 1000 to $10 \mathrm{ng} / \mathrm{ml}$. Then, the plate was sealed and incubated overnight at $4^{\circ} \mathrm{C}$. To correct the non-specific binding effects, four wells were treated with coating buffer only. After incubation, the plate was inverted to empty the contents from each well and washed four times with $300 \mu \mathrm{l}$ per well of washing buffer (PBST, $0.02 \mathrm{~mol} / \mathrm{L}$ phosphate buffer with $0.15 \mathrm{~mol} / \mathrm{L} \mathrm{NaCl}$ and $0.05 \%$ Tween-20, $\mathrm{pH}$ 7.4) to remove all unbound antigens. To block non-specific binding, $340 \mu \mathrm{l}$ of block solution (PBST with 1\% BSA) were added to and then left in all the wells for $1 \mathrm{~h}$ at $37^{\circ} \mathrm{C}$ followed by four washings with PBST. Then, 100 $\mu \mathrm{l}$ of diluted rabbit anti-carp Vtg polyclonal was added to all the wells for $2 \mathrm{~h}$ at $37^{\circ} \mathrm{C}$. After four sequential washes with PBST, to each well was added $100 \mu$ of goat antirabbit IgG conjugated to horseradish peroxidase (prepared at a final dilution of 1:1000 in PBST) and incubated for 2 $\mathrm{h}$ at $37^{\circ} \mathrm{C}$. The plate was then washed as described above. For coloration, $100 \mu \mathrm{l}$ of enzyme substrate solution was added to each well and incubated at $37^{\circ} \mathrm{C}$ in the dark for 30 min. The substrate solution was prepared by dissolving 20 $\mathrm{mg}$ of $o$-phenylenediamine (OPD, Amresco, USA) in 50 $\mathrm{ml}$ of $0.05 \mathrm{~mol} / \mathrm{L}$ phosphate-citrate buffer ( $\mathrm{pH} 5.0,0.051$ $\mathrm{mol} / \mathrm{L}$ dibasic sodium phosphate, $0.024 \mathrm{~mol} / \mathrm{L}$ citric acid); $80 \mu \mathrm{l}$ of $\mathrm{H}_{2} \mathrm{O}_{2}$ was added and mixed immediately before the solution was pipetted into the wells. The reaction was stopped after $30 \mathrm{~min}$ by the addition of $50 \mu \mathrm{l}$ of $2 \mathrm{~mol} / \mathrm{L}$ $\mathrm{HCl}$ to each well. The optical density (OD) of each well was measured at $490 \mathrm{~nm}$ using a microtiter plate reader.

\subsection{Statistical analysis}

All the data were expressed as mean \pm SD. Statistical analysis was made on raw data using SPSS statistical software for Windows, Version 11.0 (SPSS Inc., Chicago, USA). Changes of plasma Vtg were compared statistically between treatment groups and control groups by KruskalWallis one-way analysis of variance (ANOVA) followed by Dunnett's test. The statistical significant level for all data was $p<0.05$.

\section{Results and discussion}

\subsection{Acute lethality tests}

It is well known that the differences in response to toxic substances might occur amongst different species and development stages of organisms (Pascoe and Shazili, 1986; McCahon and Pascoe, 1988). Most results reported on 1,2,3,7,8-PeCDD focused on the early life stage of fish exposed via water and the toxicities of rats via oral intake (Bonati et al., 1995; Madsen and Larsen, 1989; Wisk and Cooper, 1990; Cooper and Chen, 1998; Walker and Peterson, 1991). For example, the acute $\mathrm{LD}_{50}$ of $1,2,3,7,8$ PeCDD in the eggs of rainbow trout (Oncorhynchus mykiss) is $0.566 \mathrm{ng} / \mathrm{g}$ (Walker and Peterson, 1991). This experiment was the first to determine the acute $\mathrm{LD}_{50}$ of $1,2,3,7,8-\mathrm{PeCDD}$ in juvenile goldfish in vivo, whose
$\mathrm{LD}_{50}$ value was $1.84 \mathrm{mg} / \mathrm{kg}\left(r^{2}=0.96\right)$. The significant difference between the two above-listed LD $_{50}$ suggested the fish of early life stage are far more sensitive to the toxicity of $1,2,3,7,8-\mathrm{PeCDD}$. The results of the acute lethality tests of $1,2,3,7,8-\mathrm{PeCDD}$ also demonstrated that the slope of the dose-response is steep, from $\mathrm{LC}_{10}(1.36$ $\mathrm{mg} / \mathrm{kg})$ to $\mathrm{LC}_{90}(2.48 \mathrm{mg} / \mathrm{kg})$.

The definition of the TEFs, which were used to assess the toxicity of complex mixtures containing PCDDs, was based on the induction of the AHR. The toxicity of all 2,3,7,8-substituted PCDD congeners was related to the characterization of the AHR pathway in mammals and other model organisms including zebrafish. The structurally altered AHR (H/W-type AHR) was reported to be the main factor for increased resistance of $\mathrm{H} / \mathrm{W}$ rats to TCDD $\left(\mathrm{LD}_{50}>9.6 \mathrm{mg} / \mathrm{kg}\right)$ induced lethality. The known members of the AHR pathway in zebrafish include zfAHR1 and zfAHR2. zfAHR1 is not suspected to be involved in TCDD toxicity since it does not bind to the ligand efficiently, and the H/W-type AHR had a lower molecular weight with a unique carboxyl-terminal deletion affecting the transactivation domain of the receptor (Andreasen et al., 2002a, 2002b; Klaassen, 2002; Pohjanvirta et al., 1998, 1999). But, the question of whether the goldfish had a similar structure alteration of AHR still requires further studies.

\subsection{Vitellogenin response to the exposure of $1,2,3,7,8-$ PeCDD in vivo}

\subsubsection{Development and validation of ELISA}

The optimal assay conditions were evaluated according to the results of chessboard typed titration tests, in which concentrations of both Vtg and primary antibody were varied. The combinations of coating concentrations and primary antibody diluted by 1000 yielded an optimal optical density whose values in $490 \mathrm{~nm}$ were from 0.2 to 0.9 . A standard curve of Vtg was generated to evaluate the performance of the samples, and the standard linear response curve of the indirect ELISA is shown in Fig.1. The ELISA precision (intra- and interassay variation) and the detection limit of each assay were then further analyzed. Based on

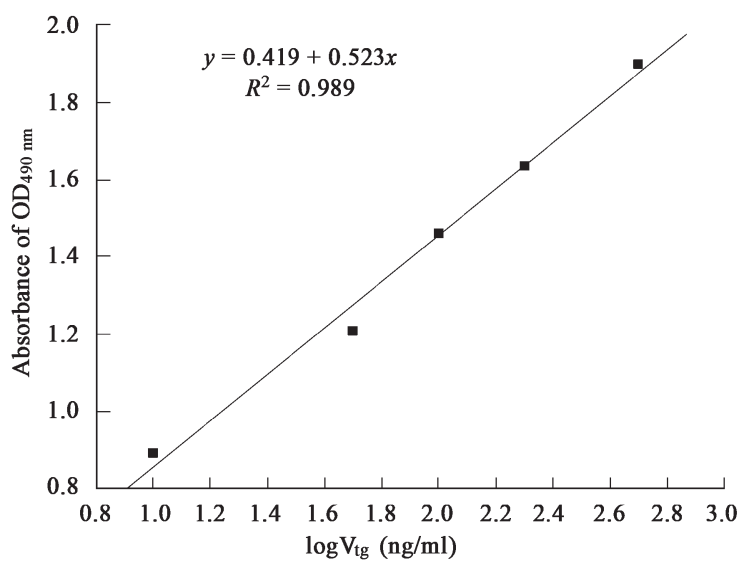

Fig. 1 Linear range of indirect ELISA standard curves of the purified Vtg from Carp with the logit transformation of the Vtg concentration. Each point represents the mean of duplicate determinations. 
the results of this assay, the range from 10 to $500 \mathrm{ng} / \mathrm{ml}$ was regarded as the low and high detection limit (OD between 0.89 and 1.99). The intra-assay variation coefficient was estimated from the duplicate $(n=4)$ calibration curves on different plates in one assay. The inter-assay variation was measured for 6 standard curves in two separate assays during 2 weeks. The coefficient of variation (CV) was calculated at the $250 \mathrm{ng} / \mathrm{ml}$ and expressed as percentage: $\mathrm{CV} \%=($ mean $\pm \mathrm{SD}) \times 100$. The intra-assay and inter-assay variations for the standard Vtg at the $250 \mathrm{ng} / \mathrm{ml}$ were $9.7 \%$ and $14.3 \%$, respectively (data not shown).

\subsubsection{Plasma vitellogenin}

In the tests, no significant induction of plasma Vtg was observed in the control groups and the $1 / 4 \mathrm{LD}_{50}$ $(0.46 \mathrm{mg} / \mathrm{kg})$ groups, but Vtg synthesis was significantly stimulated by intraperitoneal injection of $E_{2}(1 \mathrm{mg} / \mathrm{kg})$ and $1,2,3,7,8-\mathrm{PeCDD}$ in the $1 / 2 \mathrm{LD}_{50}(0.92 \mathrm{mg} / \mathrm{kg})$ groups and the $\mathrm{LD}_{30}(1.63 \mathrm{mg} / \mathrm{kg})$ groups within one week (Fig.2, $P$ $<0.01)$. A decreasing tendency was shown in the levels of plasma Vtg with increased dosages exposure to $1,2,3,7,8$ PeCDD. For instance, the level of plasma Vtg in $1 / 2 \mathrm{LD}_{50}$ group of $7 \mathrm{~d}$ was $5154 \pm 1058 \mathrm{ng} / \mathrm{ml}$, which was the highest of the 1,2,3,7,8-PeCDD exposure groups: the $4428 \pm 1487$ $\mathrm{ng} / \mathrm{ml}$ in the $1 / 2 \mathrm{LD}_{50}$ groups of $14 \mathrm{~d}$, the $4520 \pm 1688 \mathrm{ng} / \mathrm{ml}$ in $\mathrm{LD}_{30}$ groups of $7 \mathrm{~d}$, and the $2543 \pm 1018 \mathrm{ng} / \mathrm{ml}$ in $\mathrm{LD}_{30}$ groups of $14 \mathrm{~d}$. The results indicated that the estrogenic effects of 1,2,3,7,8-PeCDD could be reduced significantly within the ranges of lethality dosages in tested fish.

In recent years, it has been reported that exposure to chemicals that could interact with the endocrine system might pose a serious health hazard. An endocrine disruptor has been broadly defined as "an exogenous agent that interferes with the production, release, transport, metabolism, binding, action, or elimination of natural hormones responsible for the maintenance of homeostasis and the regulation of developmental processes". Endocrine disruptors can affect the endocrine system by at least four modes of action: serving as steroid receptors ligands, modifying steroid hormone metabolizing enzymes, perturbing hypothalamic-pituitary release of trophic hormones, and

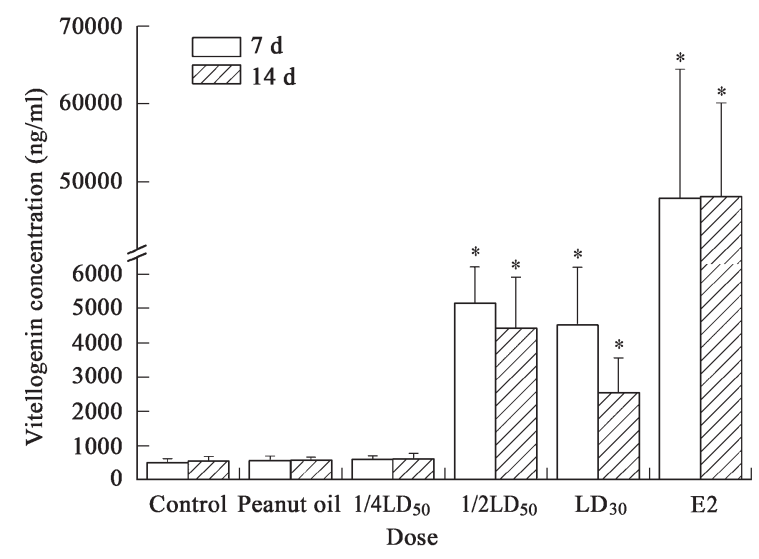

Fig. 2 Plasma vitellogenin levels in juvenile male goldfish of controls (blank, solvent and positive) and those exposed to 1,2,3,7,8-PeCDD at the doses of $1 / 4 \mathrm{LD}_{50}(0.46 \mathrm{mg} / \mathrm{kg}), 1 / 2 \mathrm{LD}_{50}(0.92 \mathrm{mg} / \mathrm{kg})$, and $\mathrm{LD}_{30}(1.63$ $\mathrm{mg} / \mathrm{kg}$ ) for 7 and $14 \mathrm{~d}$, respectively. Values were means $\pm \mathrm{SD},{ }^{*} P<0.01$. as uncharacterized proximate modes of action (Klaassen, 2002). Due to its significant induction of the plasma Vtg after one week's exposure in vivo in the $1 / 2 \mathrm{LD}_{50}$ and $\mathrm{LD}_{30}$ groups, 1,2,3,7,8-PeCDD might be one of the important contributors to the estrogenic effect of PCDDs in the environment. The toxic response of 1,2,3,7,8-PeCDD in animals is related to the transcription of AHR, and AHR can mediate the induction of the P450 isozymes (CYP 1A1 and CYP 1A2), which were reported to be associated with the metabolism of estrogens and PCDDs. However, $1,2,3,7,8-P e C D D$ was reported to be hardly oxidized by the enzymes in the short term in pregnant Long Evans rats (Chen et al., 2001; Hu and Bunce, 1999). So, further study is needed to clarify whether cytochrome P450 enzymes are involved in the pathogenesis of the estrogenic effects of 1,2,3,7,8-PeCDD in goldfish.

By testing the acute lethal dosages and the estrogenic effective dosages of 1,2,3,7,8-PeCDD in goldfish, certain relationships were found between them. According to the tendency of the dose-effect expression in the tests, it is hypothesized that the exposed dosages of 1,2,3,7,8-PeCDD around $1 / 2 \mathrm{LD}_{50}$ could stimulate the significant induction of $\mathrm{Vtg}$, and the doses within the range of lethal dosages could lead to the lethality and the significant induction of plasma Vtg at the same time after the intraperitoneal injection in juvenile male goldfish. The results also indicated that it is necessary and valuable to establish a dose-determined criterion in certain toxicant effective tests by determining the range of the exposed dosages based on the toxicant's $\mathrm{LD}_{50}$.

Due to the background exposure level of $1,2,3,7,8$ PeCDD in the environment, there was relatively low exposure risk in the lethality and estrogenic effects in goldfish. But, following the rapid economic development in China, more amounts of 1,2,3,7,8-PeCDD have been produced in related processes. The high persistence and high lipophilicity $\left(K_{\text {ow }}\right)$ of $1,2,3,7,8-P e C D D$ in the environment may lead to its gradual bioaccumulation in fish and subsequent concentration in the human body through the food chain in which fish is an important source of many essential nutrients. Certain investigations have also reported increasing blood levels of 1,2,3,7,8-PeCDD in old people having more fish in their diet and have established the long half-life of 1,2,3,7,8-PeCDD in the human body. So, there are high acute lethality dosages of 1,2,3,7,8PeCDD and a potentially high bioaccumulation of it in fish. Moreover, 1,2,3,7,8-PeCDD remains in the human body long after the contaminated fish has been eaten. Thus, it is imperative to study the relationship between the blood concentration of 1,2,3,7,8-PeCDD in the human body and acute chronic diseases caused by eating contaminated fish. Because few data are available in China on the levels of 1,2,3,7,8-PeCDD in the environmental and the body's tolerance to it, it is necessary to continue to monitor them.

\section{Conclusions}

This experiment was the first to determine the acute $\mathrm{LD}_{50}$ of $1,2,3,7,8-\mathrm{PeCDD}$ in juvenile goldfish in vivo, the 
$\mathrm{LD}_{50}$ value of $1.84 \mathrm{mg} / \mathrm{kg}$ may be valuable for further researches related to $1,2,3,7,8-\mathrm{PeCDD}$.

$1,2,3,7,8$-PeCDD might be one of the important contributors to the estrogenic effect of PCDDs in the environment because of its estrogenic effects in goldfish. It is imperative to study the relationship between the blood concentration of 1,2,3,7,8-PeCDD in human body and the acute chronic diseases, as well as to monitor the levels of this chemical component in the environment and its body's tolerance.

\section{Acknowledgements}

This work was supported by the National Natural Science Foundation of China (No. 40332023, 20621703).

\section{References}

Andreasen E A, Hahn M E, Heideman W, Peterson R E, Tanguay R L, 2002a. The zebrafish (Danio rerio) aryl hydrocarbon receptor type 1 is a novel vertebrate receptor. Mol Pharmacol, 62: 234-249.

Andreasen E A, Spitsbergen J M, Tanguay R L, Stegeman J J, Heideman W, Peterson R E, 2002b. Tissue-specific expression of AHR2, ARNT2, and CYP1A in zebrafish embryos and larvae: effects of developmental stage and 2,3,7,8-tetrachlorodibenzo-p-dioxin exposure. Toxicol Sci, 68: 403-419.

Augustowska K, Gregoraszczuk E E, Grochowalski A, Milewicz T, Mika M, Krzysiek J, Chrzaszcz R, 2003. Comparison of accumulation and altered steroid secretion by placental tissue treated with TCDD and natural mixture of PCDDsPCDFs. Reproduction, 126: 681-687.

Bonati L, Fraschini E, Lasagni M, Modoni E P, Pitea D, 1995. A hypothesis on the mechanism of PCDD biological activity based on molecular electrostatic potential modeling. Part 2. Journal of Molecular Structure: THEOCHEM, 340: 83-95.

Chen C Y, Hamm J T, Hass J R, Birnbaum L S, 2001. Disposition of polychlorinated dibenzo- $p$-dioxins, dibenzofurans, and non-ortho-polychlorinated biphenyls in pregnant long evans rats and the transfer to offspring. Toxicol Appl Pharmacol, 173: 65-88.

Chen H L, Liao P C, Su H J, GuoY L, Chen C H, Lee C C, 2005. Profile of PCDD/F levels in serum of general Taiwanese between different gender, age and smoking status. Sci Total Environ, 337: 31-43.

Cooper K, Chen C M, 1998. Toxic interaction of 2,3,7,8TCDD, 1,2,3,7,8-PeCDD, and 1,2,3,4,7,8-HeCDD: On the Japanese medaka (Oryziaas latipes). Chemosphere, 36: 189-202.

Copeland P A, Sumpter J P, Walker T K, Croft M, 1986. Vitellogenin levels in male and female rainbow trout (Salmo gairdneri Richardson) at various stages of the reproductive cycle. Comp Biochem Physiol, B83: 487-493.

Deml E, Mangelsdorf I, Greim H, 1996. Chlorinated dibenzodioxins and dibenzofurans (PCDD/F) in blood and human milk of non occupationally exposed persons living in the vicinity of a municipal waste incinerator. Chemosphere, 33 : 1941-1950.

Denslow N D, Chow M C, Kroll K J, Green L, 1999. Vitellogenin as a biomarker of exposure for estrogen or estrogen mimics. Ecotoxicology, 8: 385-398.

Fiedler H, Hutzinger D, Timms C W, 1990. Dioxins: sources of environmental load and human exposure. Toxicol Environ
Chem, 29: 157-234.

Fletcher C L, Mc K R, 1993. Polychlorinated dibenzo- $p$ dioxins (PCDDs) and dibenzofurans (PCDFs) in the aquatic environment-A literature review. Chemosphere, 26: 10411069.

Furst P, Furst C, Wilmers K, 1994. Human milk as a bioindicator for body burden of PCDDs, PCDFs, organochlorine pesticides, and PCBs. Environ Health Perspect, 102 (Suppl. 1): 187-193.

Geyer H J, Rimkus G, Scheunert I, Kaune A, Schramm K W, Kettrup A, Zeeman M, Muir D C G, Hansen L G, Mackay D, 2000. Bioaccumulation and occurrence of endocrinedisrupting chemicals (EDC) persistent organic pollutants (POPs), and other organic compounds in fish and other organisms including humans. In: Bioaccumulation, new aspects and developments. The Handbook of Environmental Chemistry (Hutzinger O., Beek B., eds.). Berlin: Springer Verlag. 2(Part J): 1-166.

Geyer H J, Schramm K W, Feicht E A, Behechti A, Kettrup A, Buters J T M, 2001. Correlation between the half-life $t_{1 / 2}$ of various xenobiotics in rats and humans. Drug Metab Rev, 33(Suppl.1): 203.

Geyer H J, Schramm K W, Feicht E A, Behechti A, Steinberg C, Bruggemann R, Poiger H, Henkelmann B, Kettrup A, 2002. Half-lives of tetra-, penta-, hexa-, hepta-, and octachlorodibenzo- $p$-dioxin in rats, monkeys, and humansa critical review. Chemosphere, 48: 631-644.

Gonzalez C A, Kogevinas M, Huici A, Gadea E, Ladona M, Bosch A, Bleda M J, 1998. Blood levels of polychlorinated dibenzodioxins, polychlorinated dibenzofurans and polychlorinated biphenyls in the general population of a Spanish Mediterranean City. Chemosphere, 36: 419-426.

Greene J F, Hays S, Paustenbach D, 2003. Basis for a proposed reference dose (RfD) for dioxin of 1-10 pg/kg-day: a weight of evidence evaluation of the human and animal studies. $J$ Toxicol Environ Health B Crit Rev, 6: 115-159.

Hu K, Bunce N J, 1999. Metabolism of polychlorinated dibenzop-dioxins by rat liver microsomes. J Biochem Mol Toxicol, 13: 307-315.

Keenan R E, Paustenbach D J, Wenning R J, Parsons A H, 1991. Pathology reevaluation of the Kociba et al. (1978) bioassay of 2,3,7,8-TCDD: implications for risk assessment. $J$ Toxicol Environ Health, 34: 279-296.

Klaassen C D, 2002. Casarett and doull's toxicology. 6th ed. Beijing: People's Medical Publishing House.

Madsen C, Larsen J C, 1989. Relative toxicity of chlorinated dibenzo-p-dioxins, and dibenzofurans measured by thymus weight and liver enzyme induction in perinatally dosed rats, 2,3,7,8-TCDD, 2,3,4,7,8-PeCDF, 1,2,3,7,8-PeCDD. Chemosphere, 18: 955-966.

McCahon C P, Pascoe D, 1988. Culture techniques for three freshwater macroinvertebrate species and their use in toxicity tests. Chemosphere, 17: 2471-2480.

Mommsen T P, Walsh P J, 1988. Vitellogenesis and oocyte assembly. In: Fish Physiology, XIA (Hoar W.S., Randall V. J., eds.). New York: Academic Press.

Noren K, Meironyte D, 2000. Certain organochlorine and organobromine contaminants in Swedish human milk in perspective of past 20-30 years. Chemosphere, 40: 11111123.

OECD, 1996, Water quality-Determination of the acute lethal toxicity of substances to a freshwater fish (Brachydanio rerio Hamilton-buchanan (Teleostei, Cyprinidae)). 2rd ed. ISO7346-1. 
Pascoe D, Shazili A M, 1986. Episodic pollution-A comparison of brief and continuous exposure of rainbow trout to cadmium. Ecotoxicology and Environmental Safety, 12: 189-198.

Pohjanvirta R, Wong J M, Li W, Harper P A, Tuomisto J, Okey A B, 1998. Point mutation in intron sequence causes altered carboxyl-terminal structure in the aryl hydrocarbon receptor of the most 2,3,7,8-tetrachlorodibenzo-p-dioxinresistant rat strain. Mol Pharmacol, 54: 86-93.

Pohjanvirta R, Viluksela M, Tuomisto J T, Unkila M, Karasinska J, Franc M A, Holowenko M, Giannone J V, Harper P A, Tuomisto J, Okey A B, 1999. Physicochemical differences in the AH receptors of the most TCDD-susceptible and the most TCDD-resistant rat strains. Toxicol Appl Pharmacol, 155: 82-95.

Schuhmacher M, Domingo J L, Llobet J M, Snderhauf W, Müller $\mathrm{L}, 1998$. Temporal variation of PCDD/F concentrations in vegetation samples collected in the vicinity of a municipal waste incinerator (1996-1997). Sci Total Environ, 218: 175-183.

Sohoni P, Tyler C R, Hurd K, Caunter J, Hetheridge M, Williams T, Woods C, Evans M, Toy R, Gargas M, Sumpter J P, 2001. Reproductive effects of long-term exposure to Bisphenol A in the fathead minnow (Pimephales promelas). Environ Sci Technol, 35: 2917-2925.

Specker J L, Sullivan G, 1994. Vitellogenesis in fish: status and perspectives. Ottawa: National Research Council of Canada.

Sun S J, Zhao J H, Liu H J, Liu D W, Ma Y X, Li L et al., 2006. Dioxin concentration in human milk in Hebei province in China and Tokyo, Japan: potential dietary risk factors and determination of possible sources. Chemosphere, 62: 1879-
1888.

Van den Berg M, Birnbaum L, Bosveld A T, Brunstrom B, Cook $\mathrm{P}$, Feeley $\mathrm{M}$ et al., 1998. Toxic equivalency factors (TEFs) for PCBs, PCDDs, PCDFs for humans and wildlife. Environ Health Perspect, 106: 775-792.

Van den Berg M, Birnbaum L S, Denison M, Vito M D, Farland W, Feeley M, et al., 2006. The 2005 World Health Organization reevaluation of human and mammalian toxic equivalency factors for dioxins and dioxin-like compounds. Toxicological Sciences, 93: 223-241.

Vartiainen T, Saarikoski S, Jaakkola J J, Tuomisto J, 1997. PCDD, PCDF, and PCB concentrations in human milk from two areas in Finland. Chemosphere, 34: 2571-2583.

Walker M K, Peterson R E, 1991. Potencies of polychlorinated dibenzo- $p$-dioxin, dibenzofuran, and biphenyl congeners, relative to 2,3,7,8-tetrachlorodibenzo- $p$-dioxin, for producing early life stage mortality in rainbow trout $(\mathrm{On}$ corhynchus mykiss). Aquatic Toxicology, 21: 219-237.

Wallace R A, 1978. Oocyte growth in non-mammalian vertebrates. New York: Plenum Press.

Wisk D J, Cooper K R, 1990. Comparison of the toxicity of several polychlorinated dibenzo- $p$-dioxins and 2,3,7,8tetrachlorodibenzofuran in embryos of the Japanese medaka (Oryzias latipes). Chemosphere, 20: 361-377.

Wittsiepe J, Schrey P, Ewers U, Lemm F, Kraft M, Eberwein G, Winneke G, Wilhelm M, 2000. Decrease of PCDD/F levels in human blood from Germany over the past ten years (1989-1998). Chemosphere, 40: 1103-1109.

Wittsiepe J, Fürst P, Schrey P, Lemm F, Kraft M, Eberwein G et al., 2007. PCDD/F and dioxin-like PCB in human blood and milk from German mothers. Chemosphere, S67: 286-294. 